\title{
Humor and sympathy in medical practice
}

\author{
Carter Hardy ${ }^{1}$ (1)
}

Published online: 21 October 2019

(c) Springer Nature B.V. 2019

\begin{abstract}
Medical professionals seem to interpret their uses of humor very differently from those outside the medical profession. Nurses and physicians argue that humor is necessary for them to do their jobs well. Many (potential) patients are horrified that they could one day be the butt of their physician's jokes. The purpose of this paper is to encourage the respectful use of humor in clinical prac-tice, so as to support its importance in medical practice, while simultaneously protecting against its potential abuse. I begin by examining two extremes of supporting or chastising the use of medical humor. I look at these views through the lenses of popular theories of humor to help explain their theoretical bases. In this second section, I explain the emotional aspect of humor as an embodied and embedded transformation of the world. This clarifies the role that humor plays in our daily lives, as well as why the ethical or unethical nature of its use is dependent on context. Third, I address the potential problems in the relationship between humor and clinical sympathy, and how this further affects the relationship between medical professionals and their patients. I conclude by arguing that humor can conflict with clinical sympathy, but this need not be the case. If medical professionals actively engage with clinical sympathy and focus on using humor in a way that is respectful towards their patients, then humor can continue to be a positive force in their lives while still providing the best care for their patients.
\end{abstract}

Keywords Humor $\cdot$ Sympathy $\cdot$ Bioethics $\cdot$ Phenomenology $\cdot$ Emotion

\section{Introduction}

Regardless of your profession, it is likely that you joke around with your coworkers. Humor is a common fixture in most of our daily lives and this is no less the case in the medical profession. However, the idea that medical professionals joke around while at work sounds odd to many outside of the medical profession. What could they possibly find so humorous in a job where patients are so often sick, injured, or dying?

Take a case that has been recounted a few times in the literature concerning medical humor:

Watson reports a story about a group of residents who ordered a pizza from their regular spot, but their regular delivery guy was mugged and killed while delivering the pizza. They all knew the delivery guy well and

Carter Hardy

chardy@ut.edu

1 Department of Philosophy and Religion, University of Tampa, 401 W. Kennedy Blvd, Mailbox R, Tampa, FL 33606, USA were in the hospital when he died. Afterwards, one joked, "What happened to our pizza?" They actually found the pizza near the ER door where the delivery guy had been mugged. Before finally eating it, one resident said, "How much do you think we ought to tip him?" (Watson 2011) ${ }^{1}$

The residents laughed and ate the pizza, but is this funny? The joke here could be that the delivery guy must warrant a massive tip because he gave his life to deliver the pizza (far over and above what would be required for a normal delivery), but also that they cannot tip the delivery guy. On the other hand, whether or not this was funny to the residents is beside the point. The ethical question people tend to have in response to this example is, should they find this funny? Was some moral imperative violated by making and/or laughing

\footnotetext{
${ }^{1}$ While a potent example, it is not the only one. There are many examples of this, such as surgeons making jokes about unconscious or sedated female patients during their surgeries (Tomlinson 2015). There is also the story of the Virginia colonoscopy patient who had his phone on to record post-surgery instruction, only to accidentally record his surgeons mocking him during the surgery (Abbott 2014). Based on the reports from medical professionals, these occurrences are not uncommon.
} 
at this joke? What jokes, if any, are morally permissible in the medical profession? The answers to these questions, as well as the solution to any ethical problems therein, will be determined by the ways in which we understand humor and the role of a medical professional.

Medical professionals seem to interpret their uses of humor within their profession the same way anyone interprets their workplace humor. Nurses and physicians argue that humor is necessary for them to do their jobs well; that it is a bonding exercise and a way to cope with the overwhelming stress of their occupations. Conversely, there are those who are disgusted that they could one day be the butt of their physician's jokes. In fact, those patients who have discovered that they were part of their physician's jokes were offended and hurt (Abbott 2014; Granek-Catarivas et al. 2005). Surely there are many patients (and potential patients) who enjoy medical humor, or at least do not mind if they are the subject of a joke or two. However, do the competing perspectives of physicians who support medical humor and those patients that resist it mean that physicians should not be allowed to joke about the patients? It seems that there can be a middle ground between abstaining from medical humor entirely or allowing all instances of humor-as indicated by the category of patients that are not bothered by medical humor. But, given the inability of physicians to immediately discern these patients from those that may be insulted, how should they decide when their jokes are morally permissible?

The purpose of this paper is to encourage the respectful use of humor in clinical practice. ${ }^{2}$ While this can serve as a general guide for all medical professionals, it is primarily directed at bioethicists. Essentially, humor has an important use in medical practice-as it does in many professionsbut it is important to make sure that medical professionals are trained to use it reflectively, and in such a way that it does not lead to oppression or abuses of already vulnerable groups.

As one final preliminary note, I will here attempt to discuss humor among medical professionals in general, even though I acknowledge the likelihood that there will be minor variations between the way that different medical professionals-such as physicians, nurses, surgeons, residents, pediatricians, and so on-make use of humor. It is my intuition that their uses of humor will share many common features. All have been known to make jokes, and there are some common features that are beneficial and others that could

\footnotetext{
${ }^{2}$ It would be an added bonus if this paper also helped to change the public opinion of everyday patients - that is, those that are not medical professionals - but that would go beyond the scope of this paper. I do think that developing a method for changing public opinion of this may be beneficial, but that will be a project for another time or for someone else to pursue.
}

count as oppressive. With that in mind, this paper is divided into four parts.

I begin by examining the two extremes of supporting or chastising the use of humor by medical professionals. I look at these views through the lenses of popular theories of humor to help explain their theoretical bases. However, finding these theories themselves wanting, I turn to a phenomenology of humor to better understand how it is experienced. In this second section, I explain the emotional aspect of humor as an embodied and embedded transformation of the world. This clarifies the role that humor can and does play in our daily lives, as well as why it is open to being used either ethically or unethically depending on the context. In the third section, I address what I interpret to be the real worry concerning medical humor: the relationship between humor and clinical sympathy. I explain the difficult relationship between humor and sympathy, and how this further affects the relationship between medical professionals and their patients. I conclude by arguing that humor can conflict with clinical sympathy, but this need not be the case. If medical professionals actively engage with clinical sympathy and focus on using humor in a way that is respectful towards their patients, then humor can continue to be a positive force in their lives while still providing the best care for their patients.

\section{Accepting or rejecting medical humor}

Many medical professionals view humor as an essential part of the medical field, with approximately $90 \%$ of medical professionals admitting to using it (Kim 2015). Some have even argued that humor is simply part of the art of learning to be a medical professional (Balakrishnan 2009; Bennett 2003; Tomlinson 2015). Some patients, on the other hand, feel that jokes against them are rude and uncaring (Robbins 2015). They are in vulnerable positions and are made even more vulnerable if they need to fear that their private medical interactions will later be a punchline. While most medical humor does not violate any confidentiality with the patient, it does seem like it violates some implicit promise of caring for the patient's stories.

The basis for these differing perspectives needs to be addressed, since they can help illuminate why the perspectives are different, as well as what ethical problems need to be solved. What is humor such that it serves such a large role in the medical profession? In this section, I explain three of the most commonly addressed theories of humor: superiority theory, incongruity theory, and relief theory. However, while each theory explains an important aspect of our experiences of humor, these theories fail to fully understand the phenomenological aspects of humor. Instead, they each focus on a 
single aspect of humor and try to fit all instances of humor into this limitation.

\section{The patient's fear of superiority theory}

The use of humor among physicians is often hidden from patients. Most jokes are told outside of exam rooms, when colleagues are on a break together, or when they go out for a drink. They are not meant to be shared with patients. However, this does not mean that jokes won't sometimes be overheard or exposed.

When exposed, the targeted patients do not often interpret these instances as "just jokes." In fact, many observers of physician-to-physician jokes tend to interpret them as dehumanizing. As Berk says, "derogatory and cynical humour as displayed by medical personnel are forms of verbal abuse, disrespect and the dehumanisation of their patients and themselves. Those individuals who are the most vulnerable and powerless in the clinical environment-students, patients and patients' families-have become the targets of the abuse" (Berk 2009, p. 7). This even occurs in medical school, in which some students interpret the jokes made by their teachers to be inappropriate.

We start to worry about humor in general when it is "directed at others who are less powerful or less fortunate than ourselves and is seen as a form of ridicule" (Cameron 2015 , p. 280). This is what some mean when they talk about the superiority theory of humor. Superiority theory argues that humor occurs when a joke or story labels an individual or group as lesser than oneself or one's own group. This would mean that when physicians make jokes about patients, it is humorous to the physicians because the jokes make them feel superior to their patients. Take the earlier example. This could mean that the residents making the joke about tipping the delivery guy is funny to them because it places them in a superior position to him. They are alive, while he is dead. Or, to interpret the scene in a more generous way, they are making the joke to feel symbolically superior to death. They laugh at the joke because it makes them feel more in control of the situation than they actually are. Physicians are using their jokes to place themselves in an even more powerful position.

This theory may capture one aspect of humor, but it is not all there is to humor. There are plenty of jokes that have nothing to do with superiority-such as nonsense jokes, which are funny because they make no sense or challenge what we think something means. Additionally, we can find plenty of things humorous without them placing us in a superior position to others. For instance, when people make jokes about themselves, their ability to laugh at themselves isn't because they feel superior to themselves.

On the other hand, it is still possible that humor can be used to make one group seem superior to another. As
Cameron notes, jokes are often "a privilege of the powerful" (Cameron 2015, p. 281). The experience of humor is largely dependent on the individual and their background, and physicians and patients are in very different situations (GranekCatarivas et al. 2005). Patients are in a vulnerable and stressful position that makes them much more at the whim of their physician. Especially when considering the different types of jokes that can be told, members of a group can tell jokes that enhance the influence of their ingroup, while at the same time demeaning the members of outgroups. In the medical field, patients are vulnerable and often at the mercy of their nurses and physicians. Jokes about patients can be seen as a method to further elevate physicians to a position of power over their vulnerable patients. In this sense, the worry is mostly with the use of an aggressive type of humor by dominant groups to target already vulnerable groups.

Aggressive humor is one of the four different styles of humor. The other three styles are self-enhancing, otherenhancing, and self-deprecating (Vallade et al. 2013). These four different styles of humor exist at a cross-section between two spectrums: positive/negative and self-directed/ other-directed. Self-enhancing jokes are positively directed at the self or ingroup. Aggressive jokes are negatively directed at the other or outgroup. Other-enhancing jokes are positively directed at the other or outgroup. Finally, self-deprecating jokes are negatively directed at the self or ingroup. It is not uncommon for two different types of humor to be used at the same time. For instance, a joke can be both aggressive towards an outgroup, while simultaneously being self-enhancing of one's self or ingroup. Many racists and sexist jokes are like this.

To rephrase what was said earlier, issues arise when aggressive jokes are used by a privileged, powerful group to target an already vulnerable group. The jokes serve as veiled insults that belittle those belonging to the target group (Saucier et al. 2016, p. 76). Furthermore, aggressive jokes against already vulnerable groups "impact subsequent evaluations of those groups' members by individuals who are exposed to the joke" (Saucier et al. 2016, p. 76). If medical students or other medical professionals overhear the jokes about patients, they will also become accustomed to evaluating patients according to the jokes. ${ }^{3}$ Those that hear these jokes, such as medical students, become more tolerant of them, and may tell similar jokes in the future. This continues to delegitimize the perspectives of patients.

Furthermore, patients are left powerless in the face of these jokes because jokes inherently allow people to dismiss

\footnotetext{
3 As Hodson and MacInnis note, "exposure to sexist jokes led to more tolerance of the discriminatory behavior. But original levels of hostile sexism moderated the effect: only those high in hostile sexism reacted to sexist jokes with greater tolerance toward a discriminatory act" (Hodson and MacInnis 2016, p. 66).
} 
moral responsibility. By this, I mean that those that are made the target of a joke are powerless to argue back because they cannot enter the conversation and enact any change in their portrayal. There are two reasons for this. First, it is not possible to argue against an emotional reaction. Second, arguing against the person that is making the joke only makes the subject of the joke look worse. The joke-teller need only claim that his or her derogatory comments are "just jokes" (Carroll 2014, p. 242; Hodson and MacInnis 2016 , p. 68), and that those who are offended merely lack a sense of humor. ${ }^{4}$ Through making patients powerless while subsequently demeaning them, patients are left even more vulnerable.

\section{Incongruity and relief theories among medical professionals}

Humor is not necessarily an attack on patients. In fact, as Robbins notes, targets of jokes are most often situations and symptoms, rather than the patients themselves; if it is about patients, it is most likely those that have "brought on their own medical problems" (Robbins 2015). The target of the humor is the illness, injury, type of patient, or the patient's poor choices. This final part is a little disconcerting, but we can at least empathize with why this may be the case: patients can often bring on their own problems, refuse to change, and then complain that medical professionals are not doing their jobs. Powerless in the face of these patients, humor may be one of the only ways to cope.

In general, the main reason that medical professionals give for using humor is that it provides some sort of relief when there is no other option. This aligns nicely with the relief theory, and is demonstrated in the pizza delivery example. Relief theory argues that we laugh when we find something to be a release of tension, or excess energy, built up in ourselves (Smuts 2009). This theory was presented by Herbert Spencer (1911), and later by Sigmund Freud (1905[1990]). In Freud's version, he argues that laughter releases psychic energy that is stored from repressed sexual and hostile feelings. As such, humor is best used when directed at those same taboo situations that are causing the repressed energy. While it can be odd to think of humor in such abstract terms of stored psychic energy, there is some good support for this theory in the more general sense of relief. Humor and laughter can help to decrease anxiety and stress (White and Winzelberg 1992). Some have even

\footnotetext{
${ }^{4}$ Sometimes, this method is even used to see if someone has the right audience for their actual beliefs and judgements. In this sense, they make a joke that is a little sexist or racist, then if the audience does not react in a positive way, the joke-teller merely has to say that he or she was "just kidding" to lessen the moral blame from the audience (Saucier et al. 2016, p. 77).
}

reported that humor has an even greater effect on reducing stress than exercise (Szabo 2004).

Returning to the pizza example once more, we can interpret humor here as a way to release the tension that accumulated after the death. The residents felt guilt and shame, and had no actual recourse to remove or handle these feelings. The joke burst that bubble and released the built-up tension. They laughed because they finally had a release for all of that energy. In effect, they were able to relax a little and return to their work. The physicians were not laughing because the delivery guy was dead, nor were they trying to diminish the seriousness of what had happened to him. Rather, they we trying to temporarily cope with the death of someone that they used to see regularly, and who they failed to save. They sought relief from their collective feelings of guilt and grief.

Another theory that may be helpful here in understanding the position of medical professionals is incongruity theory. This theory argues that humor is caused by a break in our expectations. When someone tells a joke, then suddenly plays on the words to bring about an unexpected conclusion, we find this cleverness funny. Or to be more accurate, the shift in our expectations has led to a change in what is being perceived, and this change in perception is humor. This shift is an enjoyable experience of incongruity - as opposed to an unenjoyable one, such as when something is shocking or disappointing (Dadlez 2011, p. 4; Jones 2006, p. 126; Stefanova 2012, p. 67). It is when something surprises us, but in a way that we also mark it as harmless, or even beneficial to us (Dadlez 2011, p. 4; Stefanova 2012, p. 72). However, the way that the incongruity will manifest for an individual is going to have much to do with the person in question, and the context of the joke being told. If the situation is altered, the incongruity "could be replaced by irritation, fear, anger, [or] aggression" (Stefanova 2012, p. 72).

Concerning the pizza delivery, the joke about tipping the delivery guy may be funny because it breaks with obvious expectations. Even asking the question of how much to tip is surprising, since no one at that time would think that such a question would be asked. The question simultaneously applies to the situation and breaks expectations of what should be said.

While not incorrect, incongruity theory follows superiority theory and relief theory by focusing on only one aspect of humor while ignoring the rest. Each of these theories highlights something important about the experience of different types of humor. However, the main problem here is that we have two opposing perspectives. Some are worried that physicians are using humor to take advantage of patient vulnerability. Physicians assert that they use humor as a relief for some of the immense stress of their profession. Depending on the adopted theory, we will likely take different sides. In other words, the problem here may be that people have these different theories of humor, which then affect the way 
they are interpreting the jokes. But, setting these theories aside, how is humor itself actually experienced, and why are we really worried about the use of humor in medicine? In the following section, I begin to answer this by taking a phenomenological approach to humor in order to better understand humor as it is experienced.

\section{A phenomenology of humor}

In general, humor is experienced as an enjoyable emotional state. ${ }^{5}$ Due to the complexity of emotions like humor, I will focus on four important aspects of humor that can be highlighted in the more general phenomenology of emotion: humor is (1) a transformation of the world; (2) an intentional relationship between body and world; (3) embedded in a social and historical context; and (4) below the level of the will.

To be clear, what I am not doing in this section is trying to defend an account of humor as purely an emotional state. I reject claims that there can be clear lines drawn between different affects, such as emotions, moods, and feeling. While there are some affective states that fit nicely into one type or the other, there are many more affects that are more ambiguous. Humor is one of these affective states, such that it has important emotional and feeling dimensions. For the purpose of this paper, I focus primarily on the emotional dimensions of humor. However, I will also note the feelings of humor where necessary, especially when talking about the embodiment of humor.

\section{Humorous transformations of the world}

To begin with, emotions themselves are transformations of the world (Sartre 1962, pp. 27, 39). We experience the world very differently when we are happy and when we are angry, and to transition from happiness to anger is a complete transformation of our experience. This is not to argue that emotions are things we do to transform the world. It would actually be more accurate to say that the transformation of the world $i$ the emotion. The emotion is not an object in us or in the world-it is not some subjective action that alters our perceptions of the objective world. The emotion, such as humor, is a mode of being in the world (Sartre 1962, p. 35 ). It is our relationship to the world, that can change at any moment, as if by magic (Sartre 1962, p. 40). To find

\footnotetext{
5 While it would be more accurate and complete to discuss humor as an affect in general with specific emotional dimensions, I am here choosing to focus on only these emotional dimensions of humor. This is both for the sake of simplicity and for conciseness.
}

oneself in an emotional state is to find the world appearing to oneself differently.

There is good evidence that humor is a transformation of the world (Nahas 1998, p. 664; Silva et al. 2017, p. 9; Vrticka et al. 2013, p. 860; Warren and McGraw 2016, p. 407). It alters our perceptions of self, others, and the world, making us associate enjoyment with those things. A shift from one emotion to another makes new things salient in the world, while allowing others to fade into the background. In a sense, this is precisely what the incongruity theory of humor is highlighting.

Medical teachers often use humor in teaching due to the belief that it "reduces stress, increases motivation and comprehension, and aids socialization into the profession" (Bennett 2003, p. 1259). Similarly, it can cause us to perceive topics and persons with less seriousness. This is what makes humor so useful for medical education. It can enhance education by making topics more accessible, as well as more desirable to be discussed (Nahas 1998, pp. 664-665). This is a significant transformation of perception from when we perceive the same topic through boredom or frustration. Humor opens us up to new information and focuses our attention such that we retain the information better in our memory. In boredom, information shows up as unimportant, and in frustration it shows up as threatening. Humor can also be helpful in bringing attention to serious issues in a way that will invite less pushback, distract from distressing situations, and cause persons to take themselves less seriously.

Furthermore, humor changes our perceptions of others, "decreasing social distancing" (Nahas 1998, p. 668). While this begins in medical school, it is most prominently displayed in the medical profession. Humor is often used among medical professionals to help them bond together and resist burnout (Bennett 2003; Robbins 2015). When properly utilized for those in a group, humor serves to foster a stronger feeling of community, as well as empowerment in their community. It can bring members of an ingroup closer together, causing a greater cohesion in the face of oppressive forces (Moalla 2015; Vallade et al. 2013, pp. 233-234; Vrticka et al. 2013, p. 865). Daily, medical professionals must deal with death — which they may consider a supremely oppressive force-and humor is one of the only ways to transform the situation to regain some power and control when they feel powerless to heal (Bennett 2003; Robbins 2015; Watson 2011), even if it is merely symbolic. In other words, what is usually called dark humor, or gallows humor, is learned as a useful coping strategy (Kim 2015; Oczkowski 2015; Watson 2011), and one that is equally employed in other similarly stressful professions as well (Kim 2015), albeit with less pushback. ${ }^{6}$

\footnotetext{
${ }^{6}$ Examples include law enforcement and the military.
} 


\section{The embodied intentionality of humor}

The transformation of the world that occurs in humor is tied into its intentionality, or "aboutness." While other affective states could be said to lack intentionality, such as moods (Guignon 2003, p. 188; Solomon 2006, p. 417), I am here focusing on the aspects of humor that we experience as an emotion; and one of the key features of emotions is that they have intentionality (Brentano 1971; Husserl 1989, p. 117; Merleau-Ponty 2012, p. 88; Slaby 2007, 2014; Solomon 2006). In general, to be sad is to be sad about something. To be angry to be angry about something. To experience humor is to experience something as humorous-that is, to find a joke or occurrence funny.

However, when talking about the intentionality of humor, it is important to not interpret this as something that the subject possesses that is literally pointing at something in the world. When Sartre argued that emotions are transformations of the world, he was attempting to get away from the view that emotions were things in our heads that we directed at the world (Merleau-Ponty 2012, p. 88; Sartre 1962, p. 57). Instead, they are felt relationships between oneself and the world (Merleau-Ponty 2012, p. 88; Sartre 1962). They are in the "depth" between subject and world (Cataldi 1993; Merleau-Ponty 1968), but not specifically possessed by either. As such, when the world transforms in humor, it is the subject's relationship with the intentional object that changes. When the residents made their joke about the tip, the guilty relationship that they had with the situation was briefly transformed into humor, and then they laughed.

While humor is in the space between subject and world, it is still important to note here that the subject is an embodied subject. The transformation of the world is still experienced in the subject in terms of feelings. Additionally, humor plays out across the subject's body though physiological responses, like laughter (Stefanova 2012, p. 68), which seems to be a universal experience across all cultures (Vrticka et al. 2013, p. 860). It also plays out across the subject's body in less obvious bodily responses, such as the positive health benefits of humor. ${ }^{7}$

Finally, the intentional structure in this transformation of the world is a motor intentionality (Merleau-Ponty 2012, p.

\footnotetext{
${ }^{7}$ Humor can serve as a stress-reducer, and as a way to improve one's resilience and recovery concerning challenges (Cheng and Wang 2015 , p. 761). Other noted health benefits include lowered blood pressure and anxiety, improved cognitive functioning, and improved immunity (Granek-Catarivas et al. 2005; Oczkowski 2015; Robbins 2015). For physicians, humor helps narrow interpersonal and cultural gaps, communicate difficult messages, and express frustration and anger (Granek-Catarivas et al. 2005). Though, there are those who argue that the research done on the medical benefits of humor is poorly conducted and does not sufficiently support the conclusion that it is beneficial" (Bennett 2003).
}

88; Sartre 1962, p. 50; Schmitz 2011, pp. 256-257; Slaby 2014; Solomon 2006, p. 419). Simply put, emotions are transformations of our relationship with the world, such that the world calls for some actions over others. For instance, consider when a physician must deliver serious news to a patient that may cause the patient to close off to the physician. Humor can be used to draw the patient back into discussion by transforming the patient's relationship with the topic into one where the topic is more approachable.

This may seem counter-intuitive, since the initial interpretation of humor is usually that it merely weakens the seriousness of topics. However, it should be noted that this is just a feature of the general way in which the world is transforms in humor. The transformation itself is a positive one in the sense that it is an enjoyable experience, but this can be used positively or negatively depending on what is enjoyably transformed in humor. When topics are too controversial to even begin to discuss them, people may simply try to avoid them at all costs. In these instances, humor can lessen the stigma of talking about these topics just enough to open for serious discussion. It is a delicate balance between making a topic accessible and making a mockery of it. This risk of negative consequences does not mean that humor should be entirely avoided, but rather that medical professionals need to be reflective of the jokes that they use.

The point here is that humor, like other forms of happiness, moves us towards things. It is a transformation of the world such that something shows up as more inviting than others. Specifically, the intentional object of the humor is perceived and judged as more inviting, but this experience also fills the entire experience of the world, making everything feel more approachable as well. In addition to humor being this kind of an embodied, intentional transformation of the world, it is also embedded.

\section{The embeddedness of humor}

Humor is embedded in a culture, in a context, and with others. It is dependent on context and background conditions (Nahas 1998, p. 669; Silva et al. 2017, p. 15; Stefanova 2012, p. 68), and often involves a kind of playfulness with concepts (Silva et al. 2017, p. 15; Stefanova 2012, p. 69). For instance, racist laugh at racist jokes, because of their background assumptions, group affiliations, the way they were raised, and so on (Smuts 2013, p. 55; Woodcock 2015). Likewise, one reason that physicians laugh at jokes about their patients may be because they were exposed to similar jokes from other physicians, as well as during their education. Emotions in general reveal our background valuations of the world-they are perceptions of value in the world (Scheler 1992, p. 85; Stein 1989, p. 101)—and some have even argued serve as judgments or appraisals of the world (De Sousa 2001, 2007; Lazarus 1982, 1994; Nussbaum 
1997; Solomon 1973, 1988). Different cultures are prone to finding different things humorous in different situations. The appropriateness of humor is determined by how one is raised, as well as by the situation in a culture that are deemed funny, offensive, and terrifying.

Part of this embeddedness also relates to our relationships with others. Humor is always intersubjective, since we would not have evolved to experience humor if not for our relationships with other subjects. It is a kind of communication with others that simultaneously contributes to our overall well-being (Stefanova 2012, p. 68; Vrticka et al. 2013 , p. 866) ${ }^{8}$ Likewise, humor largely relies on the existence of others in order for us to feel it. ${ }^{9}$ It is intersubjective in the sense that instances of humor almost always point to other subjects. ${ }^{10}$ Overall, humor is important to our interpersonal interactions and the maintenance of our relationships in social interactions. This can be demonstrated by those who have difficulty understanding humor, and likewise have difficulty with social interactions, such as those with autism (Wu et al. 2016). ${ }^{11}$

\footnotetext{
${ }^{8}$ I want to be careful here, because I do not want to make such a strong claim that we never experience humor when we are alone. On the other hand, while I can experience humor when alone, it is either still directed at others or it is experienced very differently than humor with others. What I mean is that it often lacks expression, making the experience of humor weaker. This difference in experience is supported by research that shows we are less likely to express humor when alone. While humor can be experienced alone, it is more often (and primarily) an intersubjective experience (Barber 2015). We are less likely to laugh if there are no others around. Some have argued that this is because humor acts as "a form of communication[which] could be positive (for example 'breaking the ice' in a difficult and very serious situation, relaxing the atmosphere) or negative (involuntary or intended sarcasm, mockery, demonstration of superiority)" (Stefanova 2012, p. 67). We use humor to convey information about ourselves and our opinions of others in a relatively safe way. As a form of communication, humor is experienced in a weaker state if there is no one else around to continue the humor-dialogue.

${ }^{9}$ For instance, I can feel happy or sad in relation to merely myself or something happening in the world, but intersubjective emotions, like empathy, require there to be someone else with whom I empathize. The same goes for sympathy, guilt, love, and so on.

${ }^{10}$ Whether we are talking about superiority theory, incongruity theory, or relief theory, others are an important part of humor. For incongruity, it is others that tell us jokes or humorous stories, creating instances in which we will find incongruity. For superiority, it is over others that jokes make us feel superior.

11 As Wu et al. say, "the lack of a sense of humor might be one of the reasons that people with autism frustrated in social interaction" (Wu et al. 2016, p. 25). Though, it is worth noting that individuals with autism responded to nonsense jokes a lot more normally than incongruity jokes (Wu et al. 2016, p. 26). The authors note that this difficulty partly stems from "deficits in theory of mind" (Wu et al. 2016, p. 290), or a difficulty understanding the mental states of others, such as the intentions of their jokes.
}

\section{Humor and free will}

Finally, humor is not something that we directly control. To find something funny happens in an instant. We do not stop, deliberate, then laugh - that is, unless we do not get the joke. Once the joke is understood, the humor is immediate. In other words, humor is like all emotions in that humor exists below the level of the will (Merleau-Ponty 2012, p. 166; Schmitz 2011, p. 254). We find ourselves in emotional states and it is often very difficult to control these or break free of them. When I find something funny, my perceptions of the world are usually already transformed before I become aware of my humor.

Furthermore, we do not immediately control what we find humorous, nor can we control when we stop finding something humorous. For instance, there are times when we can become immune to jokes after hearing them too often. This is a kind of "humor burnout" in which things that we would normally judge as being comical or amusing are no longer experienced as such (Stefanova 2012, p. 69). This is also akin to what happens with other affects, like compassion fatigue, where one's emotional responses become worn out from over-exposure (Kretz 2014, p. 343).

In sum, humor is like other emotions in that it is an embodied transformation of one's relationship with the world based on one's personal background and cultural context. We often find ourselves already experiencing humor, and this affects our perceptions, beliefs, and judgments. Specific to humor is the positive valence and the way that the intentional object shows up in humor as less serious and more approachable. Due to the way in which humor is experienced, and the ways that it affects our perceptions of the world, its use in the medical profession is open to being interpreted as desirable or deplorable. In other words, humor itself is not inherently good or bad-it does not by its very nature create some essential superiority relationship, nor does it act as a relief for all those involved. Instead, we can root the ethical problems with humor in the way that it is used to transform the world, as well as how this transformation moves the medical professionals who experience humor. This appears to revel the real problem with medical humor: that the transformation could conflict with how we want patients to be transformed for medical professionals. Specifically, it would be a problem if patients are transformed into jokes rather than subjects of care. This is the problematic relationship between humor and clinical sympathy.

\section{Humor and the problem of sympathy}

Like empathy, sympathy is an intersubjective affect that is helpful for improving patient care (Hardy 2017, 2019). It encourages better communication and a greater investment 
in the patient's wellbeing. If humor replaces this emotional response to the patient, then the worry is that medical professionals will grow more distant from their patients-they will not care enough about them to properly examine and treat them. If this is the case, then some worry that physicians will end up missing important, life-saving information (Kim 2015). But, is this necessarily the case? Does all medical humor necessarily supplant care? Even if some medical humor does this, I argue in the next two sections that there is a way to allow for medical humor and also maintain clinical sympathy. The first step it to address what is meant here by sympathy.

To begin with, when I say that there could be a conflict between humor and sympathy, what I actually mean is that humor may undermine certain morally valued sympathetic responses - "genuine sympathy"-with morally reprehensible ones. The reason I say this is because I support Scheler's phenomenology of sympathy.

While sympathy is the focus for Scheler in his 1954 work, The Nature of Sympathy, as well as here, he also spends time distinguishing it from similar intersubjective affects. This is worth doing here as well to be as clear as possible about Scheler's theory of sympathy. Among the other affects that he addresses are emotional sharing (Mitfühlen), sympathy (Mitgefühl), emotional contagion (Gefühlsansteckung), and a feeling of oneness (Einsfühlung) (Scheler 1954, pp. liii, 12; Scheler 1992, p. 59). Unlike many others, Scheler begins from an intersubjective standpoint when addressing affectivity. We always already exist with others in the world, so an experience of an affect is always intersubjective. This would mean that sympathy, as well as some other intersubjective affects, are fundamental features of our lives.

To begin with, he defines sympathy as a "fellow-feeling 'about something'; rejoicing in his joy and commiseration with his sorrow" (Scheler 1954, p. 12). It is an understanding of the other's emotional state with the addition of an emotional response that has the other's emotional state as its intentional object. For instance, if my friend gets good news about the success of a medical treatment and he is joyous about it, then a sympathetic reaction from me may be to feel happy for my friend's happiness. Though, it should also be noted, despite this example, that one's own feeling and its intentional object do not need to match (Scheler 1954, pp. 13-14). One could also be sad about a friend's guilt and it would still fall into the realm of sympathy, even though sadness and guilt are not the same emotion. This is the feature of sympathy that separates it from both emotional sharing and emotional contagion. In sympathy, " $m y$ commiseration and his suffering are phenomenologically two different facts, not one fact," whereas they are the same emotional state in both emotional contagion and emotional sharing. ${ }^{12}$

Emotional sharing is when one is in the same emotional state as the other. It is not the case that each is merely directed at the same object in a similar way. Rather, the emotional state is fully shared by each person, such that one person's experience of the emotion is reliant on the other person also experiencing the emotion. It is a "feeling-in-common" (Scheler 1954, p. 13). The example Scheler uses to explain this phenomenon is that of grieving parents (Scheler 1954, p. 12). Imagine a morbid situation in which a child has died and both parents of the child feel grief. Scheler argues that it would not usually be right to say that the mother feels grief and the father feels a different grief. The child is the focus of both of their intentions, they both have the same past (more or less) with the child, and they are both confronted with the same experience of knowing that the child is dead. Accordingly, the mother and father share their grief.

Additionally, Scheler argues that it would be inaccurate to say that the father or mother is only feeling grief because the other is feeling grief, which will be closer to Scheler's description of emotional contagion. Their grief is something that they share. It is a state that they are both in, and that they are both sustaining. Though, to be fair, Scheler doesn't give much of an explanation as to why we should not just interpret this as two very similar, but still independent emotional reactions. He expects it to be obvious that the parents' grief is one and the same.

\footnotetext{
12 I could also talk here about the difference between sympathy and a feeling of oneness - or true emotional identification (Scheler 1954, p. 18). It is "the act of identifying one's own self with that of another... it is not only the separate process of feeling in another that is unconsciously taken as one's own, but his self (in all its basic attitudes), that is identified with one's own self" (Scheler 1954, p. 18). As Bornemark explains it, Einsfühlung is "an act where a unity between oneself and the other is experienced. It is a rare experience where the other is identified with what is one's own in a pre-conscious and unconditional way" (Bornemark 2014, p. 363). All of the other's basic attitudes - all of the other's intentions and desires, emotions and feelings, and so on-are identified with my own. In this sense, Scheler calls emotional identification a "limiting case" of emotional contagion, since the latter only involves the other's feeling being taken as one's own, but not identification between selves (Scheler 1954, p. 18). What he means here is that I take more than merely the other's emotions as being associated with my own (Scheler 1954, p. 18). In emotional contagion, the other's emotion is adopted as if it were my own. In emotional identification, the other's entire self is involuntarily taken as being identified with my own. Emotional identification can be distinguished from sympathy due to the distance that sympathy allows between the self and other (Scheler 1954, p. 23). Emotional identification is not an emotional reaction to the other's emotional reaction, since this would mean that my identification with the other is completely separate from the other. In sympathy, I can feel a wide variety of emotions towards others, but this doesn't mean that I truly identify myself with them.
} 
Emotional contagion is different from emotional sharing. It is when one automatically adopts the intentional state of the other (Scheler 1954, pp. 14-15). This is different from sympathy for two reasons. The first is that, in emotional contagion, the emotional state actually is the same kind of emotional state being experienced by the other. Whereas with sympathy, one can feel sad about another's anger, emotional contagion involves one being happy because the other is happy and sad because the other is sad. As Scheler says, "here there is neither a directing of feeling towards the other's joy or suffering, nor any participation in her experience. On the contrary, it is characteristic of emotional infection that it occurs only as a transference of the state of feeling" (Scheler 1954, p. 15). The other's state is transferred to me and I adopt it as my own. In fact, it is often the case that I fully believe the emotion to be my own, and never think to attribute its source to the other.

The second reason that emotional contagion is different from sympathy is that it doesn't require an understanding of the other's emotional state (Scheler 1954, p. 15). In sympathy, it is necessary that I understand the other's emotional state, since it is the intentional object of the emotion. This understanding doesn't need to be a deep understanding, such as when one has undergone, or is currently undergoing, the emotion oneself. Rather, understanding here is meant in a weaker sense of being able to attribute the emotion to the other. In emotional contagion, the other's emotion overcomes me, without my needing to acknowledge that the other is in the same emotional state. I often believe that the emotion is entirely my own-not being shared with or adopted from anyone else-even if I had no experience to warrant the emotion. For instance, after a long day, I may be grouchy and upset, but after talking to a friend who is in a much better mood than myself, I notice my mood has significantly improved. I find myself happy, even though nothing has changed about my long, tiring day. I could easily attribute my happiness to my friend's happiness, but this is not necessary. ${ }^{13}$

Both emotional sharing and contagion can be distinguished from sympathy, since sympathy includes the distinction between "vicariously visualized feeling, and participation in feeling" (Scheler 1954, p. 14). I must be able to understand the other's emotional state if I am going to

\footnotetext{
13 Scheler also argues that it is not necessary that another person be in the emotional state that I have caught (Scheler 1954, p. 15). In other words, it is not necessary that I catch the emotion from another person. Scheler explicitly notes that one can catch an emotion from objects or the environment, "such as the serenity of a spring landscape, the melancholy of a rainy day, the wretchedness of a room" (Scheler 1954, p. 15). In these examples, we adopt the emotion from the environment in the same way we catch it from others, even if we do not explicitly attribute that emotion to the landscape and we think that the emotion is entirely our own.
}

sympathize with it, but this understanding of the other's emotion does not need to equate to my experience of the same affect. The parents of a deceased patient may feel the same grief towards their lost child (emotional sharing), but the physician who sympathizes with their grief does not directly share their grief; instead the grief is vicariously visualized so the physician can join them in their grieving, which is done by having other negative feelings directed at their grief (Vandenberghe 2008, p. 39). A physician can understand that a patient is suffering and feel badly about the patient's experience without suffering themselves. The other's feeling and my own are two separate experiences.

An example that may help stress this point is Scheler's own example of "the cruel man," which he claims to be "the very opposite of an (associated) act of fellow-feeling" (Scheler 1954, p. 14). As Vandenberghe notes, this person "intentionally feels with his victim in order to maximize the infliction of pain offers another, more perverse example of fellow-feeling" (Vandenberghe 2008, p. 39). That is, the cruel person feels with the victim-vicariously visualizing the victim's pain - and feels enjoyment towards this visualized pain. This, however, is not a genuine sympathy since it is dissociated from the other. In this example, the cruel man understands the other's state of emotional suffering, but feels joy in relation to it. This has the same structure as genuine sympathy in that it understands a feeling and responds with a directed feeling, but it is different in that there is a disassociation between the feelings. In a similar vein, genuine sympathy does not require the actual experience of the same affect-since this would be either emotional sharing or contagion—but it does require that sympathy be guided by love.

For Scheler, love is a kind of positive valuation of people and objects in the world. More accurately, it is the perception of the greatest possible potential value in the intentional object (Scheler 1954, pp. 140-141; Vandenberghe 2008, p. 29). ${ }^{14}$ While it is the guiding force of genuine sympathy, love is distinguished from sympathy itself in at least three ways. First, love involves this valuation where sympathy does not (Scheler 1954, p. 141). Sympathy is directed at actual others, where love "addresses the "ideal other" (Vandenberghe 2008 , p. 40). Even self-love involves a valuation of oneself in a way that sympathy cannot, since we cannot sympathize with ourselves (Scheler 1954, p. 141). Second, sympathy is a fellow-feeling, but love (for Scheler) is "not a 'feeling' (i.e. a function), but an act and a movement" (Scheler 1954, p. 141). It is a movement towards higher value. This is more

\footnotetext{
${ }^{14}$ In his work, "Ordo Amoris", Scheler even claims that if we can understand the ordo amoris-or, the order of love-of another person, then we understand the person (Scheler 1973, p. 100). This is because we would be able to see through the other person's eyes and understand the way that they person values the world based on the things that he or she loves, as well as how they are being loved.
} 
akin to how I described emotions earlier, as well as their motor intentionality. Third, Scheler notes that love is spontaneous while sympathy is reactive (Scheler 1954, p. 142). That is, sympathy is a feeling that responds to a feeling in the other, and as such can only be directed at feeling others. Love is not bound by this limitation, and can instead be directed at anything (Scheler 1954, p. 142).

Despite these differences, love and sympathy are still intimately intertwined. Specifically, love does not depend on sympathy but sympathy does depend on love. The level and kind of love that underlies sympathy will determine the degree to which sympathy is experienced (Scheler 1954, p. 142). The same is true of empathy (Vandenberghe 2008, p. 26). We can, however, have sympathy towards those that we do not love, but this is usually because we have a more general love for that person as being a member of a loved group (Scheler 1954, p. 142). The experience that he says is impossible is sympathizing with those that we hate-at least at the same time that we feel hate towards them (Scheler 1954, p. 143).

In sum, sympathy is a feeling that has the other's feeling as its intentional object. It is not a direct feeling of the other, but rather an understanding of the other's feeling with the addition of an emotional response. When guided by love, this feeling is of the same valence, such that we feel bad when our loved ones are sad or angry and we feel positively when they are happy.

\section{Clinical sympathy and humor}

Sympathy is useful to medicine in that it connects physicians to their patients and moves them to help their patients in a way that is lacking with a purely naturalistic, objective, scientific approach to patients. Elsewhere, I call this clinical sympathy, which is "a reflective, affective response to the patient, where the reflection couples an attunement to one's own affective response with an understanding of how one's affects are influencing one's beliefs and judgments" (Hardy 2019). This reflective understanding of one's own emotional responses and how they are affecting perceptions and judgments is a skill that must be learned for all emotions, not just humor. It is easy to fall into a passive relationship with our own emotions, but doing so open us up to experiencing the wrong emotions at the wrong times.

With this definition of sympathy, it can be seen clearly how humor is a kind of emotional response that can replace genuine sympathy. The problem here, in a moral sense, is that this can be interpreted as mocking patients rather than caring for them. Humor is powerful in the way that it subverts other emotional responses-particularly moral ones like shame, anger, and so on. When humor takes the place of moral emotions, it reduces the desired moral responses (Mallett et al. 2016, 272). This is not unique to humor, but it is significantly dangerous concerning humor due to the way the world transforms in humor. As noted earlier, it causes the intentional object of humor to be perceived in a less serious way-as something lighter and less threatening. This, however, can be threatening to patient care when the patient is the intentional object. Some patients worry about being belittled or mocked by these jokes.

However, looking back to the kinds of jokes addressed earlier in this paper, jokes that mock others are only one kind of joke. This fits the definition of aggressive humor which are those jokes meant to belittle the other. These jokes demonstrate a lack of respect and care for patients. Telling jokes in this sense would be a moral problem if they were the only jokes that could be told, but they are not. Physicians can also tell jokes that mock themselves (in order to make themselves seem more accessible to patients) or that enhance patients (in order for patients to feel more comfortable and confident). These two ways of using humor with patients can actually be immensely beneficial for patient care. Given the need for clinical sympathy and the need to avoid belittling jokes towards vulnerable patients, I offer the following solutions.

To begin with, humor itself should not be entirely avoided, but rather needs to be used carefully. When reflecting on the use of humor, it is best to follow two guidelines in order to ensure respect and care. First, it is best to make use of humor that is either self-deprecating, other-enhancing, or self-enhancing. This makes it so that those who are most vulnerable are not the ones that are the butt of the joke. It also maintains the physician in a kind of shared vulnerability with the patient, rather than using aggressive humor to make the patient alone more vulnerable.

Second, if aggressive jokes are to be used, it is probably best if they are only directed at general situations and symptoms, so that specific patients are never mistakenly taken as the object of the humor. This will make it less likely that humor will be inadvertently trained as the habitual response to patients instead of genuine clinical sympathy. If this were to happen, then it would interfere with their patient care. Also, because medical professionals and students cannot necessarily control what they will initially find humorous, it is best to just avoid those jokes that could be directed at patients. This way they can avoid them being trained into habits. Jokes can be also be morally permissible if they are about patient types or typical situations, but they risk being disrespectful when directed at specific patients.

My worry here is that unreflective use of aggressive humor can lead to a pattern of disrespect, and by extension a lower level of care. If most patient-directed humor fails to be both reflective and attuned to the relevant affective responses, then medical professionals are not thinking about the way that their perceptions of their patients are 
transformed in humor, and they are not necessarily attuned to the emotional responses and needs of their patients either. Medical professionals and students alike merely hear others telling these aggressive jokes-sometimes their role models - and take this as a mark of the profession. They pick up the practice and make similar jokes - the habit of which will carry on into their professional lives. I don't deny that this can have benefits in terms of bonding for medical professionals, but it can become a problem if it becomes the norm that patients are transformed into humorous objects rather than subjects deserving care. Medical professionals hold a high level of moral responsibility, so there needs to be more reflection concerning how and when humor is used.

One problem here is that there are patients who will be offended to be a part of a joke, even if it is not aggressive towards the patient. That is, it is always possible for the patient to be over-sensitive and complain about their care just because of a joke. Concerning this point, it should not be assumed that medical professionals who tell jokes actually lack care simply because patients interpret medical humor as insulting or dehumanizing (Robbins 2015). There can still be genuine clinical sympathy even when medical humor is used. The problem is how it is directed at the intentional object of the humor. If the humor is intended to make fun of patients, then it would make sense for patients to be offended. However, if the jokes are meant to enhance patients or to merely make fun of symptoms and situations, then there can still be genuine sympathy towards patients. The two need not conflict any more than, for example, love and annoyance conflict. Just because someone is annoyed by some action of their beloved does not mean that they do not love their beloved. Love and annoyance can be experienced simultaneously. Likewise, humor and care can also be experienced simultaneously - and because of the coping and bonding benefits of humor, they should both be experienced by medical professionals. ${ }^{15}$ It would be too quick to simply chastise all uses of medical humor. However, an allowance of humor should not imply that all humor should be allowed. We should still discourage humor that can be damaging to patients (Oczkowski 2015; Robbins 2015; Watson 2011). Concerning humor, we need a greater focus on clinical sympathy and humor's role in it.

\footnotetext{
15 I would also argue that this applies to more than just the relationship between humor and sympathy. In general, the use of humor needs to be carefully balanced with other emotions. We don't want our medical professionals to merely laugh off all conflicts and difficulties. Likewise, we also want medical professional to train themselves experience other emotions at the right time and place, including care, guilt, anger, and even pride. All of these emotions have an important place in the morality medical practice.
}

\section{References}

Abbott, Ryan. 2014. Unconscious Patient Says Doctors Mocked Him. Courthouse News 22 April 2014. Accessed 9 July 2015.

Balakrishnan, V. 2009. The Making of a Physician. Mens Sana Monographs 7 (1): 184-188.

Barber, Michael. 2015. Making Humor Together: Phenomenology and Interracial Humor. Societàmutamentopolitica 6 (12): 43-66.

Bennett, Howard. 2003. Humor in Medicine. Southern Medical Journal 96 (12): 1257-1261.

Berk, Ronald. 2009. Derogatory and Cynical Humour in Clinical Teaching and the Workplace: The Need for Professionalism. Medical Education 43: 7-9.

Bornemark, Jonna. 2014. The Genesis of Empathy in Human Development: A Phenomenological Reconstruction. Medicine, Health Care and Philosophy 17 (2): 259-268.

Brentano, Franz. 1971. Psychology from the Empirical Standpoint (trans: Terrell, D.B.). London: Routledge and Kegan Paul.

Cameron, John. 2015. Can Poverty be Funny? The Serious Use of Humour as a Strategy of Public Engagement for Global Justice. Third World Quarterly 36 (2): 274-290.

Carroll, Noël. 2014. Ethics and Comic Amusement. British Journal of Aesthetics 54 (2): 241-253.

Cataldi, Sue L. 1993. Emotion, Depth, and Flesh: A Study of Sensitive Space. Reflections of Merleau-Ponty's Philosophy of Embodiment. New York: State University of New York Press.

Cheng, David, and Lu Wang. 2015. Examining the Energizing Effects of Humor: The Influence of Humor on Persistence Behavior. Journal of Business and Psychology 30: 759-772.

Dadlez, E.M. 2011. Truly Funny: Humor, Irony, and Satire as Moral Criticism. The Journal of Aesthetic Education 45 (1): 1-17.

De Sousa, Ronald. 2001. Moral Emotions. Ethical Theory and Moral Practice 4 (2): 109-126.

De Sousa, Ronald. 2007. Truth, Authenticity, and Rationality. Dialectica 61: 323-345.

Freud, Sigmund. 1905[1990]. Jokes and Their Relation to the Unconscious (trans: James Strachey). New York: W. W. Norton \& Company.

Granek-Catarivas, M., S. Goldstein-Ferber, Y. Azuri, S. Vinker, and E. Kahan. 2005. Use of Humour in Primary Care: Different Perceptions Among Patients and Physicians. Postgraduate Medical Journal 81: 126-130.

Guignon, Charles. 2003. Moods in Heidegger's Being and Time. In What is an Emotion? Classic and Contemporary Readings, ed. Robert C. Solomon, 180-190. Oxford: Oxford University Press.

Hardy, Carter. 2017. Empathizing with Patients: The Role of Interaction and Narratives in Providing Better Patient Care. Medicine, Health Care and Philosophy 20 (2): 237-248.

Hardy, Carter. 2019. Clinical Sympathy: The Important Role of Affectivity in Clinical Practice. Medicine, Health Care and Philosophy. https://doi.org/10.1007/s11019-018-9872-8.

Hodson, Gordon, and Cara C. MacInnis. 2016. Derogating Humor as a Delegitimization Strategy in Intergroup Contexts. Translational Issues in Psychological Science 2 (1): 63-74.

Husserl, Edmund. 1989. Ideas Pertaining to a Pure Phenomenology and to a Phenomenological Philosophy (Vol. 3, Second Book: Studies in the Phenomenology of Constitution) (trans: Richard Rojcewicz, Andre Schuwer). Boston: Kluwer Academic Publishers.

Jones, Ward. 2006. The Function and Content of Amusement. South African Journal of Philosophy 25 (2): 126-137.

Kim, Jean. 2015. Should Health Care Providers Joke About Patients? Medical Gallows Humor can Help Providers Cope, But at Want Cost? Psychology Today, 26 Feb 2015. Accessed 9 July 2019. 
Kretz, Lisa. 2014. Emotional Responsibility and Teaching Ethics: Student Empowerment. Ethics and Education 9 (3): 340-355.

Lazarus, Richard. 1982. Thoughts on the Relations Between Emotion and Cognition. American Psychologist 37 (9): 1019-1024.

Lazarus, Richard. 1994. Appraisal: The Minimal Cognitive Prerequisites of Emotion. In The Nature of Emotion: Fundamental Questions, ed. Paul Eckman and Richard J. Davidson. New York: Oxford University Press.

Mallett, Robyn K., Thomas E. Ford, and Julie A. Woodzicka. 2016. What Did He Mean by That? Humor Decreases Attributions of Sexism and Confrontation of Sexist Jokes. Sex Roles 75: 272-284.

Merleau-Ponty, Maurice. 1968. The Visible and the Invisible. Evanston, IL: Northwestern University Press.

Merleau-Ponty, Maurice. 2012. Phenomenology of Perception (trans: Landes, Donald A.). New York: Routledge.

Moalla, Asma. 2015. Incongruity in the Generation and Perception of Humor on Facebook in the Aftermath of the Tunisian Revolution. Journal of Pragmatics 75: 44-52.

Nahas, Violeta Lopez. 1998. Humour: A Phenornenological Study within the Context of Clinical Education. Nurse Education Today 18: 663-672.

Nussbaum, Martha. 1997. Emotions as Judgements of Value and Importance. In Relativism, Suffering and Beyond: Essays in Memory of Bimal K. Matilal, ed. P. Bilimoria and J.N. Mohanty. New Delhi: Oxford University Press.

Oczkowski, Simon. 2015. Virtuous Laughter: We Should Teach Medical Learners the Art of Humor. Critical Care 19: 222-223.

Robbins, Alexandra. 2015. Nurses Make Fun of Their Dying Patients. That's Okay. The Washington Post 16 April 2015. Accessed 9 July 2019.

Sartre, Jean-Paul. 1962. Sketch for a Theory of the Emotions. New York: Routledge Classics.

Saucier, Donald A., Conor J. O’Dea, and Megan L. Strain. 2016. The Bad, the Good, the Misunderstood: The Social Effects of Racial Humor. Translational Issues in Psychological Science 2 (1): $75-85$.

Scheler, Max. 1954. The Nature of Sympathy (trans: Heath, Peter). London: Routledge \& Kegan Paul LTD.

Scheler, Max. 1973. Selected Philosophical Essays. Evanston, IL: Northwestern University Press.

Scheler, Max. 1992. On Feeling, Knowing and Valuing. Chicago: University of Chicago Press.

Schmitz, Hermann. 2011. Emotions Outside the Box-The New Phenomenology of Feeling and Corporeality. Phenomenology and the Cognitive Sciences 10: 241-259.

Silva, et al. 2017. Seeing the Funny Side of Things: Humour Processing in Autism Spectrum Disorders. Research in Autism Spectrum Disorders 43-44: 8-17.

Slaby, Jan. 2007. Affective Intentionality and the Feeling Body. Phenomenology and the Cognitive Sciences 7: 429-444.

Slaby, Jan. 2014. Emotion and Agency. In Emotion and Value, ed. S. Roeser and C. Todd. Oxford: Oxford University Press.
Smuts, Aaron. 2009. Do Moral Flaws Enhance Amusement? American Philosophical Quarterly 46 (2): 151-162.

Smuts, Aaron. 2013. The Salacious and the Satirical: In Defense of Symmetric Comic Moralism. The Journal of Aesthetic Education 47 (4): 45-63.

Solomon, Robert C. 1973. Emotions and Choice. Review of Metaphysics 28 (1): 20-41.

Solomon, Robert C. 1988. On Emotions as Judgments. American Philosophical Quarterly 25 (2): 183-191.

Solomon, Robert C. 2006. Emotions in Continental Philosophy. Philosophy Compass 1 (5): 413-431.

Spencer, Herbert. 1911. On the Physiology of Laughter. Essays on Education Etc.. London: Dent.

Stefanova, Ana. 2012. Humour Theories and the Archetype of the Trickster in Folklore: An Analytical Psychology Point of View. Fokelore 50 (50): 63-86.

Stein, Edith. 1989. On the Problem of Empathy. Third Revised (trans: Stein, Waltraut). Washington, DC: ICS Publications.

Szabo, Attila. 2004. The Acute Effects of Humor and Exercise on Mood and Anxiety. Journal of Leisure Research 35 (2): 152-162.

Tomlinson, Tom. 2015. Humor in Medicine: Nasty, Dark, and Shades of Grey. MSU Bioethics 29 Sept. 2015. Center for Ethics and Humanities in the Life Sciences at Michigan State University. Accessed 9 July 2019.

Vallade, Jessalyn I., Melanie Booth-Butterfield, and Lori E. Vela. 2013. Taking Back Power: Using Superiority Theory to Predict Humor Use Following a Relational Transgression. Western Journal of Communication 77 (2): 231-248.

Vandenberghe, Frédéric. 2008. Sociology of the Heart: Max Scheler's Epistemology of Love. Theory, Culture and Society 25 (3): 17-51.

Vrticka, Pascal, Jessica M. Black, and Allan L. Reiss. 2013. The Neural Basis of Humour Processing. Nature Reviews Neuroscience 14: $860-868$.

Warren, Caleb, and A. Peter McGraw. 2016. Differentiating What is Humorous from What is Not. Journal of Personality and Social Psychology 110 (3): 407-430.

Watson, Katie. 2011. Gallows Humor in Medicine. The Hastings Center Report 41 (5): 37-45.

White, Sabina, and Andrew Winzelberg. 1992. Laughter and Stress. Humor 5: 343-355.

Woodcock, Scott. 2015. Comic Immoralism and Relatively Funny Jokes. Journal of Applied Philosophy 32 (2): 203-216.

Wu, C.L., et al. 2016. Effectiveness of Humor Training Among Adolescents with Autism. Psychiatry Research 246: 25-31.

Publisher's Note Springer Nature remains neutral with regard to jurisdictional claims in published maps and institutional affiliations. 